\title{
Effects of Human Activities in the Middle Drainage Area on the Lower Channel as Influenced by the Xiaobeiganliu River Reach, Yellow River
}

\author{
Li He* \\ Key Laboratory of Water Cycle and Related Land Surface Processes, Institute of Geographic Sciences \\ and Natural Resources Research, Chinese Academy of Sciences, Beijing, China
}

Received: 7 July 2017

Accepted: 4 March 2018

\begin{abstract}
The fluvial processes of sediment-laden flow running through the Xiaobeiganliu (XBGL) River reach changed dramatically after the year 2000 . Thus, the connection between the sediment source area (area between Toudaoguai and Longmen) and the lower channel requires further analysis. This study aims to investigate the effects of human activities in the drainage area of Toudaoguai-Longmen on XBGL River reach and the Lower Yellow River (LYR). Prior to 1999, deposition in XBGL was positively correlated with inflow sediment and runoff entering the river reach. The correlation between these two variables became negative after 1999. The ratios between deposition in XBGL and change of runoff and sediment by human activities in the upper drainage area were 0 in 1971-1984, 0.15 in 1985-1998, and -0.39 in 1999-2012. For the changed deposition processes of the XBGL, the ratios between deposition in the LYR and change of runoff and sediment by human activities in the upper drainage area were 0.87 in 1971-1984, 0.92 in 1985-1998, and 2.33 in 1999-2012. The analyses revealed the important role of XBGL in sediment storage in the river system, where the decrease in inflow suspended sediment load of XBGL results in a likely increase in the outflow of the river reach.
\end{abstract}

Keywords: human activities, drainage area between Toudaoguai and Longmen, Xiaobeiganliu River reach, Lower Yellow River

\section{Introduction}

Water runoff in the Yellow River (YR) basin is mainly from the drainage area of the upper Lanzhou $(\sim 60 \%)$, and the sediment is mainly eroded from the middle reach across the Loess Plateau ( 90\%) [1]. The drainage area between Toudaoguai (TDG) and Longmen

*e-mail: heli@igsnrr.ac.cn
(LM) is a major part of the coarse sediment source area (CSSA) in the Loess Plateau, and the ratio of sediment eroded from this drainage area is approximately $60 \%$ [1]. Since 1999, the "Grain for Green" project has been increasing vegetable coverage on the steep hillsides of CSSA [2]. The sediment delivery modulus in the CSSA decreased from an average of $7767.4 \mathrm{t} /\left(\mathrm{km}^{2} \cdot \mathrm{a}\right.$ ) (in the years 1951-1969) to $980.5 \mathrm{t} /\left(\mathrm{km}^{2}\right.$ a) (in 2000-2010) [2]. Sediment eroded from the upper drainage area presented a dramaticcally decreasing trend, along with streamflow 
and suspended sediment load in the Lower Yellow River (LYR) [3-8].

The Xiaobeiganliu (XBGL) River reach connects the drainage area of TDG-LM (i.e., sediment source area) and LYR (i.e., sediment deposition area). As a closely connected system, the change in sediment and water runoff in the upper drainage areas may affect the fluvial process of the lower channel after the XBGL River

a)

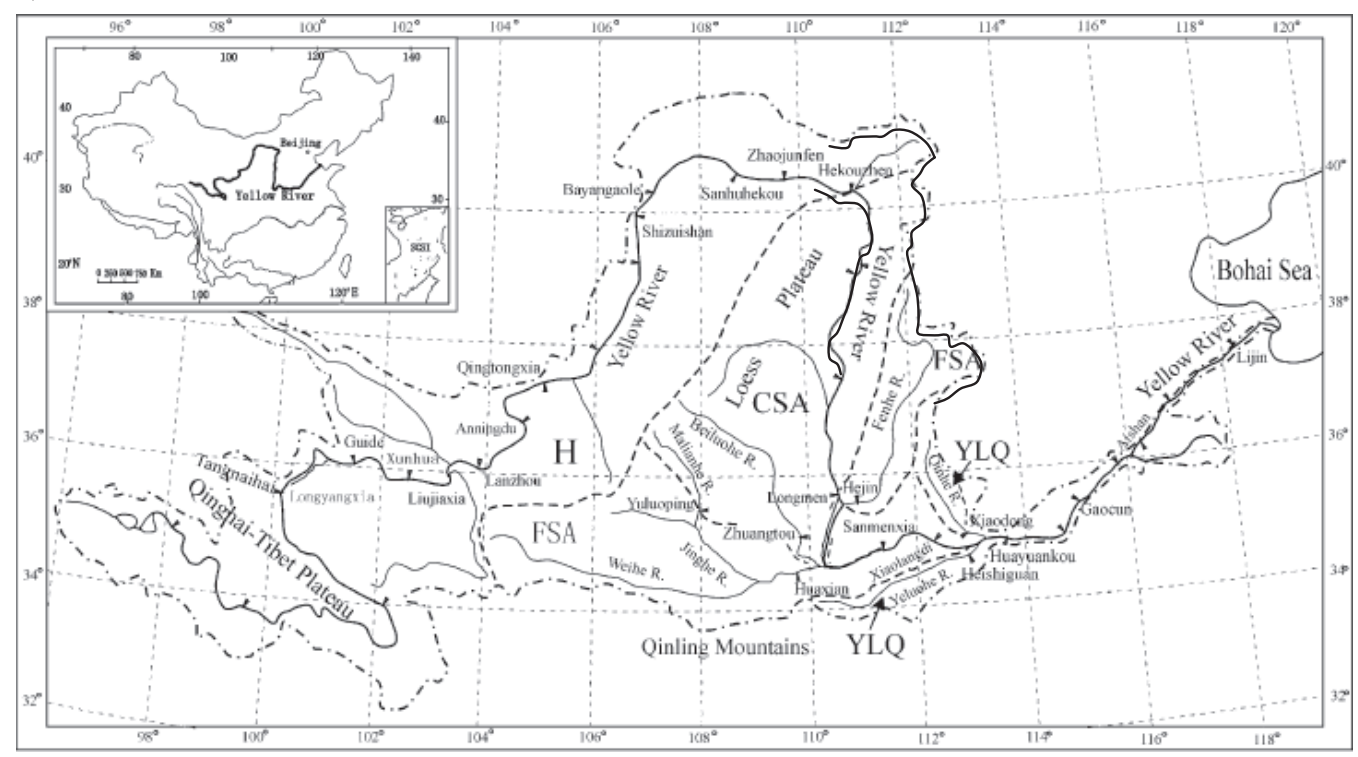

b)

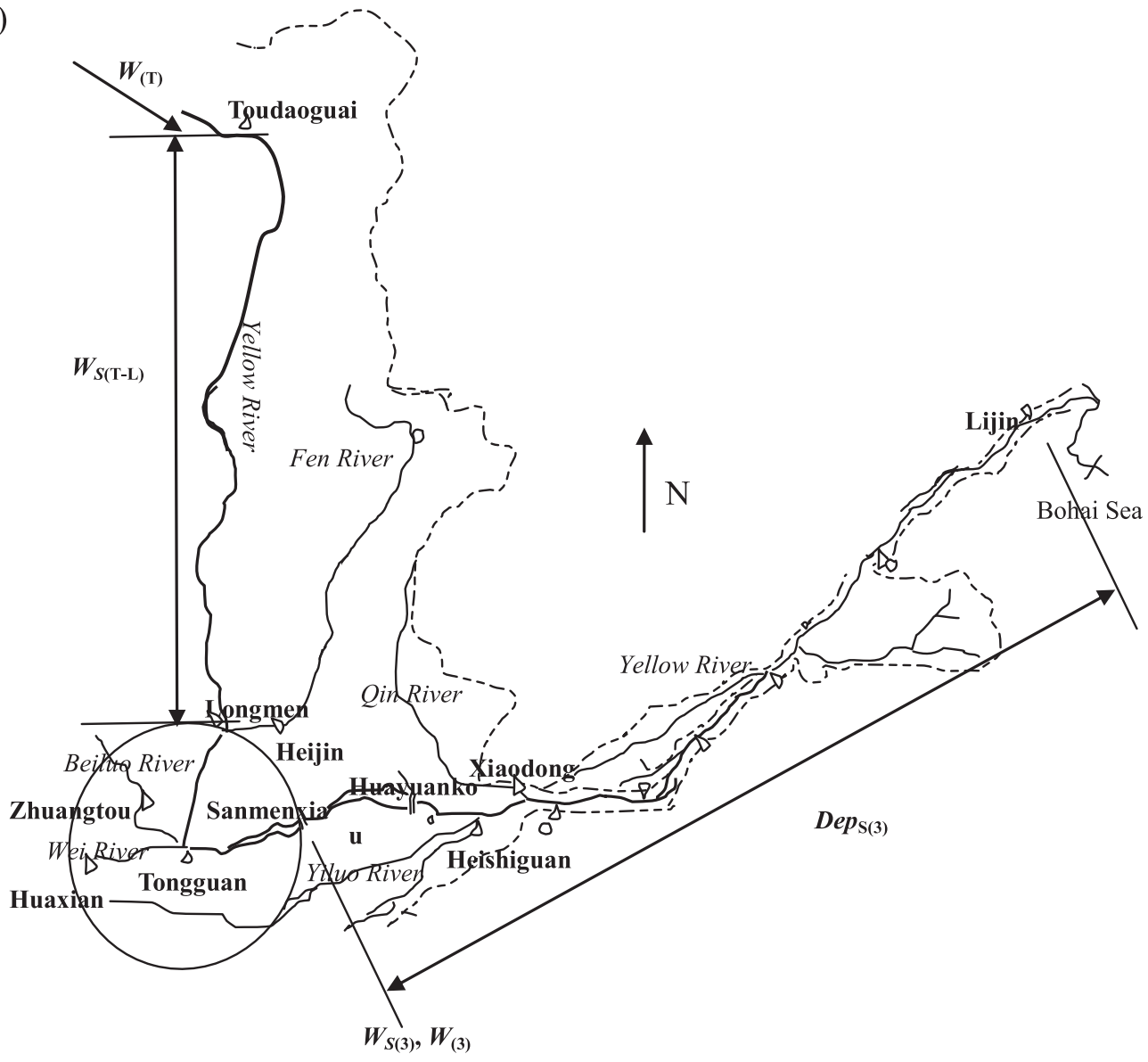

Fig. 1. Maps of the Middle and the Lower Yellow River; $W_{(T)}$ represents runoff from the drainage area in upper Toudaoguai, $W_{S(T-L)}$ represents SSL eroded from the drainage area between Toudaoguai and Longmen, $W_{(3)}$ and $W_{S(3)}$ represent the runoff and SSL entering the lower channel, respectively, and $D e p_{S(3)}$ means deposition in the lower channel. a) The entire Yellow River, b) Relationship between the Middle Yellow River and the Lower Yellow River. 
reach adjustment. The XBGL River reach may change the regime of sediment-laden flow entering the local river reach. The changed sediment regime of floods flowing out of the local river reach will, in turn, lead to different fluvial processes in the succeeding channel. Therefore, the effects of adjustment (i.e., deposition) of XBGL may affect the relationship between the upland area and the lower channel. The local fluvial process of XBGL has been widely analyzed [9]. However, previous studies focused on the local channel only, and no attention has been paid to the relationship between sediment source and deposition areas. The relationship between deposition in the LYR and the change in runoff and SSL from different upper regions has also been widely discussed [10-11]. These relationships are expressed as fitted experimental equations or constant coefficients. Fitted equations expresses the adjusting effect of XBGL while indicating the compound effects of human activities and climate change [10-11]. Constant coefficients distinguish the effect of human activities but ignores the temporal variation of changed environmental conditions [12-13]. The fluvial processes of XBGL have changed dramatically in recent years [9]. Therefore, analyzing the relationship between change in runoff and sediment load from the upper drainage area and deposition in the LYR with the changed adjusting effect of XBGL is imperative. Given the large percentage of human activities that contribute to these changes [12], our analysis must focus on the effect of human activities in the upper drainage area. A better understanding of the relationship between human activities in upper drainage areas and the associated effects on the LYR stem channel is useful for soil and water conservation, eco-rehabilitation, and river basin management. It may also benefit LYR management, except for the local drainage area.

Therefore, the current study aims to investigate the relationship between change in runoff and SSL by human activities in the middle YR on the LYR after adjustment of XBGL as deposition. First, the amounts of decreased runoff and sediment load by human activities at the LM station are collected. Measured data at the upstream boundaries of XBGL and the corresponding depositions are then collected to fit the relationship between deposition and inflow conditions. The double-mass-curve (DMC) method is used to analyze the changing point of this relationship. Finally, the corresponding change in deposition caused by the change in runoff and sediment load entering the river reaches is estimated for XBGL and LYR.

\section{Materials and Methods}

\section{Drainage Area}

As shown in Fig. 1a), the length of the stem channel of the middle YR reach between TDG and Huayuankou (HYK) is approximately $1206 \mathrm{~km}$, and the drainage area is approximately $34 \times 10^{4} \mathrm{~km}^{2}$. Water and sediment from the middle reaches account for $44.3 \%$ and $88.2 \%$, respectively $[14,15]$. The average annual precipitation in the middle YR is approximately $530 \mathrm{~mm}$, and the average annual temperature varies from 8 to $14^{\circ} \mathrm{C}[16$, 17].

From TDG to LM station, the YR runs through the continuous Jin-Shan Valley as its main course. At the same time, tributaries in this area run through the Loess Plateau, which is the main sediment source area of YR [18]. From 1919 to 1985, the loess Plateau loses approximately 1.5 billion tons of sediment to the YR every year $[19,20]$.

The channel length of the XBGL River reach between LM and Tongguan (TG) stations is approximately $132.5 \mathrm{~km}$ [19]. Channel width ranges from $3.5 \mathrm{~km}$ to $19 \mathrm{~km}$, with an average of $8.5 \mathrm{~km}$ $[18,19]$. Channel slope is approximately $0.03-0.06 \%$. The controlling stations of XBGL are LM and TG stations, as well as Hejin (HJ), Huaxian (HX), and Zhuangtou (ZT) stations for the three tributaries of YR [21, 22], namely the Fen, Wei, and Beiluo Rivers, respectively (Fig. 1b).

\section{Methodology}

The influence of human activities in the TDG-LM drainage area on the channel system (XBGL and LYR) is analyzed based on empirical formulas. Fig. 2 shows the steps for estimating the relationship between the change in SSL and runoff caused by human activities in the TDG-LM drainage area and the deposition in the LYR.

\section{Effects of Human Activities}

The controlling station of the TDG-LM drainage area is the LM station, and the change in runoff and

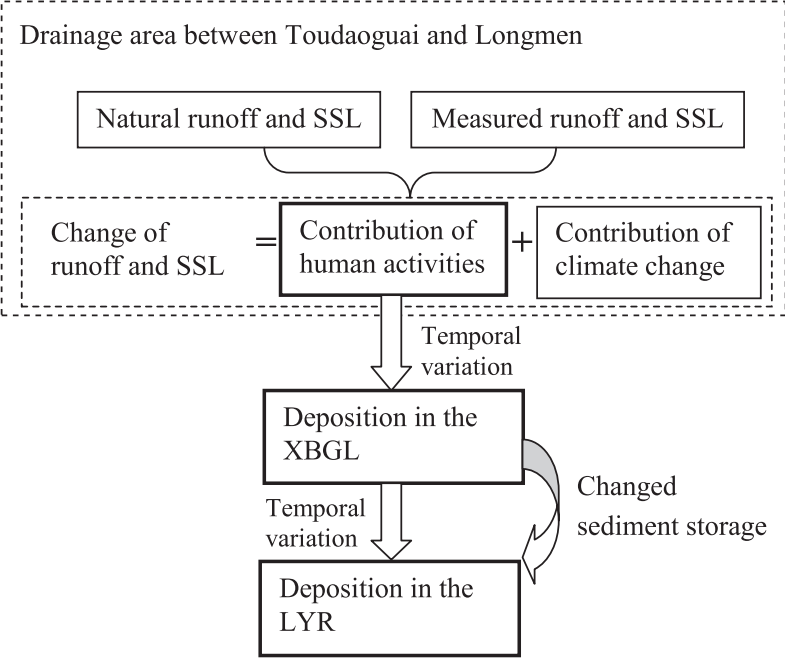

Fig. 2. Sketch map of the analysis procedure. 
SSL in this drainage area can be determined using data measured at LM. The effect of human activities can be expressed in the following equations:

$$
\begin{gathered}
W_{N(L M)}-W_{(L M)}=\Delta W_{\text {Human }(L M)}+\Delta W_{C \text { limate }(L M)}(1) \\
W_{N, S(L M)}-W_{S(L M)}=\Delta W_{S(\text { Human }),(L M)}+\Delta W_{S(\text { Climate }),(L M)}
\end{gathered}
$$

...where $W$ and $W_{S}$ represent annual runoff and SSL, respectively; subscript $N$ indicates natural values; subscript $L M$ indicates LM station; $\Delta W$ and $\Delta W_{S}$ are the annual change in inflow of runoff and SSL, respectively; and subscripts Human and Climate indicate the change in runoff by human activities and climate change, respectively. As the present study focuses on the effects of human activities, only the first items at the right-hand side (RHS) of Eqs. (1) and (2) are analyzed. To enhance readability, the subscript Human is omitted when such omission does not lead to misunderstanding.

Measured and natural runoff and SSL data should be collected first. Measured runoff and SSL can be found in the yearbooks published by the Yellow River Conservation Committee (YRCC); these are estimated by using the difference between data measured at the TDG and LM stations. Natural runoff and SSL data can be estimated by adding runoff consumed by agricultural irrigation, industrial and domestic water consumption, flood diversion, and water storage by soil and water conservation measures [23-26]. The contribution ratios of human activities and climate change have also been widely investigated [27-36]. Thus, runoff and SSL reduced by human activities in the TDG-LM drainage area by human activities $\left(\Delta W_{S(L M)}\right.$ and $\left.\Delta W_{(L M)}\right)$ can also be estimated [17, 34, 36-39].

\section{Inflow of the Two River Reaches}

The change in inflow conditions of the two river reaches can be expressed as

$$
\Delta W_{(X B G L)}=\Delta W_{(L M)}+\Delta W_{(H J)}+\Delta W_{(H X)}+\Delta W_{(Z T)}
$$

$$
\Delta W_{S(X B G L)}=\Delta W_{S(L M)}+\Delta W_{S(H J)}+\Delta W_{S(H X)}+\Delta W_{S(Z T)}
$$

...where $\Delta W_{(X B G L)}$ and $\Delta W_{S(X B G L)}$ represent the annual change in inflow of XBGL (positive for decrease in inflow). The subscripts $L M, H J, H X$, and $Z T$ represent the LM, HJ, HX, and ZT stations, respectively. The three tributaries, namely the Fen, Wei, and Beiluo Rivers, may not be analyzed. Moreover, the three items on the RHS of Eqs. (3) and (4) equal zero. Therefore, runoff from these three tributaries are assumed to be constant and do not influence $\Delta W_{(X B G L)}$ and $\Delta W_{S(X B G L)}$.
For the LYR, the expressions are as follows:

$$
\begin{gathered}
\Delta W_{(3)}=\Delta W_{(H Y K)}+\Delta W_{(H S G)}+\Delta W_{(X D)} \\
\Delta W_{S(3)}=\Delta W_{S(H Y K)}+\Delta W_{S(H S G)}+\Delta W_{S(X D)}
\end{gathered}
$$

...where $\Delta W_{(3)}$ and $\Delta W_{S(3)}$ represent the annual change of inflow in the LYR (positive for decrease in inflow). The subscripts $H Y K, H S G$, and $X D$ represent HYK, Heishiguan (controlling station of the Yiluo River), and Xiaodong (controlling station of the Qin River). The two tributaries (i.e., Yiluo and Qin Rivers) may not be included, and the two items on the RHS of Eqs. (5) and (6) equal zero. Thus, runoff from these two tributaries are assumed to be constant and do not influence $\Delta W_{(3)}$ and $\Delta W_{S(3)}$.

Water diversion and SSL dredged from the two river channels (i.e., $X B G L$ and $L Y R$ ) are not considered inflow conditions. These two parts are also assumed to be constant during the analysis. Hence, these two parts are not included in Eqs. (3) to (6).

\section{Relationship between the Two River Reaches}

The relationship of change of runoff between the three parts $(L M, X B G L$, and $L Y R)$ can be expressed as:

$$
\Delta W_{(L M)}=\Delta W_{(X B G L)}=\Delta W_{(3)}
$$

...where $\Delta W_{(L M)}, \Delta W_{(X B G L)}$, and $\Delta W_{(3)}$ indicate the annual change in runoff $\left(10^{8} \mathrm{~m}^{3}\right)$ (positive for decrease in runoff). The $\Delta W_{(X B G L)}$ and $\Delta W_{(3)}$ may not be changed by other human activities, except when influencing $\Delta W_{(L M)}$. The annual change in runoff inflow at LM (drainage area in upper LM) is transmitted to the lower channel without any loss. The influence of the Xiaolangdi and Sanmenxia reservoirs may not be considered because the first item on the RHS of Eq. (5) equals that of LM.

The relationship of the change in SSL between these three parts can be expressed as:

$$
\Delta W_{S(L M)}-\Delta D e p_{S(X B G L)}=\Delta W_{S(3)}
$$

...where $\Delta W_{S(L M)}$ and $\Delta W_{S(3)}$ indicate the annual change (positive for decrease) in SSL entering XBGL and LYR $\left(10^{8} \mathrm{t}\right)$, respectively; and $\triangle D e p_{S(X B G L)}$ denotes the change in deposition (positive for decrease) in the XBGL $\left(10^{8} \mathrm{t}\right)$. The first item on the RHS of Eq. (6) equals that of LM, and no deposition may occur in the Xiaolangdi and Sanmenxia reservoirs.

The current work aims to analyze the impact of human activities in the TDG-LM drainage area on XBGL and LYR. As mentioned previously, $\Delta W_{(L M)}$ in Eqs. (3) and (7), and $\Delta W_{S(L M)}$ in Eqs. (4) and (8) mean $\Delta W_{(\text {Human })(L M)}$ and $\Delta W_{S(\text { Human })(L M)}$, respectively. Hence, $\Delta W_{(X B G L)}$ and $\Delta W_{(3)}$ in Eqs. (3) and (7) may also indicate contributions by human activities. If $\Delta D e p_{S(X B G L)}$ in 
Eq. (8) is the amount caused by human activities, then $\Delta W_{S(3)}$ may also indicate the effects of human activities. The assumption indicates that runoff and SSL caused by human activities at the $L M$ station may not be diverted.

Therefore, the key concern is to identify the relationship between the change in SSL and runoff $\left(\Delta W_{S(L M)}\right.$ and $\left.\Delta W_{(L M)}\right)$ and the change in deposition in $X B G L\left(\triangle D e p_{S(X B G L)}\right)$. To assess the relationship among these three variables $\left(\Delta D e p_{S(X B G L)}, \Delta W_{S(L M)}\right.$, and $\left.\Delta W_{(L M)}\right)$, the DMC method is adopted to determine the correlation between accumulated deposition and accumulated SSL and runoff.

\section{Deposition in XBGL}

DMC theory states that the cumulative of one variable against the cumulative of another related variable for a concurrent period will plot as a straight line if the two variables are proportional; the line slope will represent the constant of proportionality between the two variables. However, a break in the slope of $\mathrm{DMC}$ can be identified in the curves, suggesting a change in the constant of proportionality between the two variables. The difference in the slope of the lines on either side of the break indicates the degree of change in the relationship. Searcy et al. [40] provided a detailed analysis of DMC and applied it to check the long-term shifts of a hydrological record and the relationships between two hydrological records.

The DMC method is a simple and practical tool for identifying the changes in a river response due to recent anthropogenic disturbances [41]. In this study, the DMC method was employed to determine the breaking points of the relationship between cumulative deposition $\left(\Sigma D e p_{S(X B G L)}\right)$ and cumulative SSL, and runoff entering $\mathrm{XBGL}\left(\Sigma W_{S(X B G L)}\right.$ and $\left.\Sigma W_{(X B G L)}\right)$. The relationship among these three variables is fitted with measured data using the following:

$$
\sum \operatorname{Dep}_{S(X B G L)}=f\left(\sum W_{S(X B G L)}, \sum W_{(X B G L)}\right)
$$

...where $\Sigma W_{(X B G L)}$ and $\Sigma W_{S(X B G L)}$ are the accumulated runoff $\left(10^{8} \mathrm{~m}^{3}\right)$ and $\mathrm{SSL}\left(10^{8} \mathrm{t}\right)$ entering $X B G L$, respectively, and $\Sigma D e p_{S(X B G L)}$ is the accumulated deposition in $X B G L$.

\section{Deposition in the LYR}

Various fitted equations can be used to investigate the relationship between deposition in the lower reach and inflow conditions from the upper stream. When the formula by $\mathrm{Xu}$ [10] is adopted, the annual deposition in the LYR based on data in 1950-1997 can be estimated as

$$
\operatorname{Dep}_{S(3)}=a_{1} W_{S(3)}-b_{1} W_{(3)}+c_{1}
$$

...where $\operatorname{Dep}_{S(3)}$ is the annual deposition in the reach of Sanmenxia-Lijin $\left(10^{8} \mathrm{t}\right), W_{S(3)}$ is the annual SSL $\left(10^{8} \mathrm{t}\right)$, and $W_{(3)}$ is the annual runoff $\left(10^{8} \mathrm{~m}^{3}\right)$. The inflow of the LYR can be calculated as the sum of data measured at HYK (on the YR), HSG, and XD stations [10]. The values of $a_{1}, b_{1}$, and $c_{1}$ are $0.507,0.0192$, and 3.84 , respectively.

When the incoming runoff and SSL are changed, the deposition in the LYR may change correspondingly:

$$
\Delta \operatorname{Dep}_{S(3)}=a_{1} \Delta W_{S(3)}-b_{1} \Delta W_{(3)}
$$

...where $\Delta D e p_{S(3)}$ indicates the annual change in deposition of the LYR $\left(10^{8} \mathrm{t}\right)$, and $\Delta W_{S(3)}$ and $\Delta W_{(3)}$ are expressed in units of $10^{8} \mathrm{t}$ and $10^{8} \mathrm{~m}^{3}$, respectively. The ratio $a_{1} / b_{1}$ is 26.4 . To maintain the quasi state of the lower channel $\left(\Delta D e p_{S(3)}=0\right)$, the change in sediment load may also lead to an increase in the water amount available in the lower channel.

\section{Data Collection}

The first part of the collected data provides the changes in runoff and SSL caused by human activities in the TDG-LM drainage area, which are the first items on the RHS of Eqs. (1) and (2).

The second part of the collected data consists of measurements at the LM, HJ, ZT, and HX stations. These data are used to evaluate the temporal variation in inflow conditions of XBGL. Runoff and SSL data measured at the LM station (and the HJ station) and deposition in XBGL $\left(\operatorname{Dep}_{S(X B G L)}\right)$ can be adopted to fit Eq. (9).

Runoff and sediment load data, namely, $W_{(3)}$ and $W_{S(3)}$, measured at several other stations (i.e., HYK, HSG, and XD) must also be collected in order to estimate deposition in the LYR $\left(D e p_{S(3)}\right)$ using Eq. (11). All these data are measured and published in yearbooks by the YRCC.

\section{Results}

\section{Relationship between Inflow and Deposition in XBGL}

The temporal variation in runoff and SSL at different stations are listed in Table 1. The deposition in XBGL shows a decreasing trend, especially after 2000.

The relationship between accumulated deposition in XBGL $\left(\Sigma\left(\operatorname{Dep}_{S(X B G L)}\right)\right)$ and its inflow $\left(\Sigma\left(W_{S(X B G L)}\right)\right.$ and $\left.\Sigma\left(W_{(X B G L)}\right)\right)$ are shown in Fig. 3. The accumulated sediment deposition in XBGL increased with accumulated runoff before 1970 and remained constant during the period of 1971-1984. These two variables manifested positive correlation after 1984. However, the positive correlation before 1998 changed to a negative one after 1999. The relationship between accumulated sedimentation and accumulated sediment load is almost the same as that of runoff, as shown in Fig. $3 b$. 
Table 1. Average annual runoff and SSL along the Middle Yellow River.

\begin{tabular}{|c|c|c|c|c|c|c|c|c|}
\hline \multirow{2}{*}{ Stations } & \multicolumn{2}{|c|}{$1957-1979$} & \multicolumn{2}{|c|}{$1980-1999$} & \multicolumn{2}{c|}{$2000-2012$} & \multicolumn{2}{|c|}{$1957-2012$} \\
\cline { 2 - 10 } & $\begin{array}{c}\text { Runoff } \\
\left(10^{8} \mathrm{~m}^{3}\right)\end{array}$ & $\begin{array}{c}\text { SSL } \\
\left(10^{8} \mathrm{t}\right)\end{array}$ & $\begin{array}{c}\text { Runoff } \\
\left(10^{8} \mathrm{~m}^{3}\right)\end{array}$ & $\begin{array}{c}\text { SSL } \\
\left(10^{8} \mathrm{t}\right)\end{array}$ & $\begin{array}{c}\text { Runoff } \\
\left(10^{8} \mathrm{~m}^{3}\right)\end{array}$ & $\begin{array}{c}\text { SSL } \\
\left(10^{8} \mathrm{t}\right)\end{array}$ & $\begin{array}{c}\text { Runoff } \\
\left(10^{8} \mathrm{~m}^{3}\right)\end{array}$ & $\begin{array}{c}\text { SSL } \\
\left(10^{8} \mathrm{t}\right)\end{array}$ \\
\hline TDG & 246 & 1.52 & 197.6 & 0.69 & 162.1 & 0.44 & 201.9 & 0.88 \\
\hline LM & 310.4 & 10.64 & 237.2 & 4.9 & 182.8 & 1.6 & 243.5 & 5.71 \\
\hline TDG-LM & $\mathbf{6 4 . 4}$ & $\mathbf{9 . 1 2}$ & $\mathbf{3 9 . 6}$ & $\mathbf{4 . 2 1}$ & $\mathbf{2 0 . 7}$ & $\mathbf{1 . 1 6}$ & $\mathbf{4 1 . 6}$ & $\mathbf{4 . 8 3}$ \\
\hline TG & 406.9 & 14.83 & 309.1 & 7.85 & 228 & 2.83 & 314.7 & 8.5 \\
\hline LM-TG & $\mathbf{9 6 . 5}$ & $\mathbf{4 . 1 9}$ & $\mathbf{7 1 . 9}$ & $\mathbf{2 . 9 5}$ & $\mathbf{4 5 . 2}$ & $\mathbf{1 . 2 3}$ & $\mathbf{7 1 . 2}$ & $\mathbf{2 . 7 9}$ \\
\hline ZT & 445.8 & 12.77 & 334.3 & 7.29 & 251.3 & 1.04 & 343.8 & 7.03 \\
\hline TG-HYK & $\mathbf{3 8 . 9}$ & $\mathbf{- 2 . 0 6}$ & $\mathbf{2 5 . 2}$ & $\mathbf{- 0 . 5 6}$ & $\mathbf{2 3 . 3}$ & $\mathbf{- 1 . 7 9}$ & $\mathbf{2 9 . 1}$ & $\mathbf{- 1 . 4 7}$ \\
\hline TDG-HYK & $\mathbf{1 9 9 . 8}$ & $\mathbf{1 1 . 2 5}$ & $\mathbf{1 3 6 . 7}$ & $\mathbf{6 . 6}$ & $\mathbf{8 9 . 2}$ & $\mathbf{0 . 6}$ & $\mathbf{1 4 1 . 9}$ & $\mathbf{6 . 1 5}$ \\
\hline HJ $^{\text {a }}$ & $\mathbf{1 5 . 2 7}$ & $\mathbf{0 . 4 1}$ & $\mathbf{5 . 8 7}$ & $\mathbf{0 . 0 4}$ & $\mathbf{4 . 5 3}$ & $\mathbf{0 . 0 0}$ & $\mathbf{9 . 8 2}$ & $\mathbf{0 . 2 0}$ \\
\hline ZT $^{\text {a }}$ & 7.97 & 0.93 & 8.16 & 0.70 & 6.21 & 0.17 & 7.60 & 0.67 \\
\hline HX $^{\text {b }}$ & 80.26 & 4.17 & 61.41 & 2.78 & 42.21 & 1.40 & 68.13 & 3.25 \\
\hline Deposition in XBGL & & $1.32{ }^{\mathrm{d}}$ & & 0.46 & & -0.26 & & $\mathbf{0 . 6 2}$ \\
\hline LM+HJ+ZT+HX-TG & & 1.32 & & 0.57 & & 0.34 & & 1.33 \\
\hline
\end{tabular}

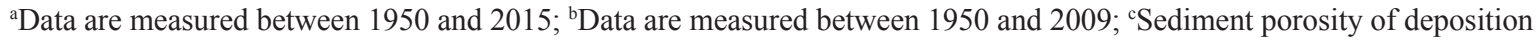
in the XBGL river reach is $1440 \mathrm{~kg} / \mathrm{m}^{3}$; ${ }^{\mathrm{d}}$ Data cover $1960-1979$
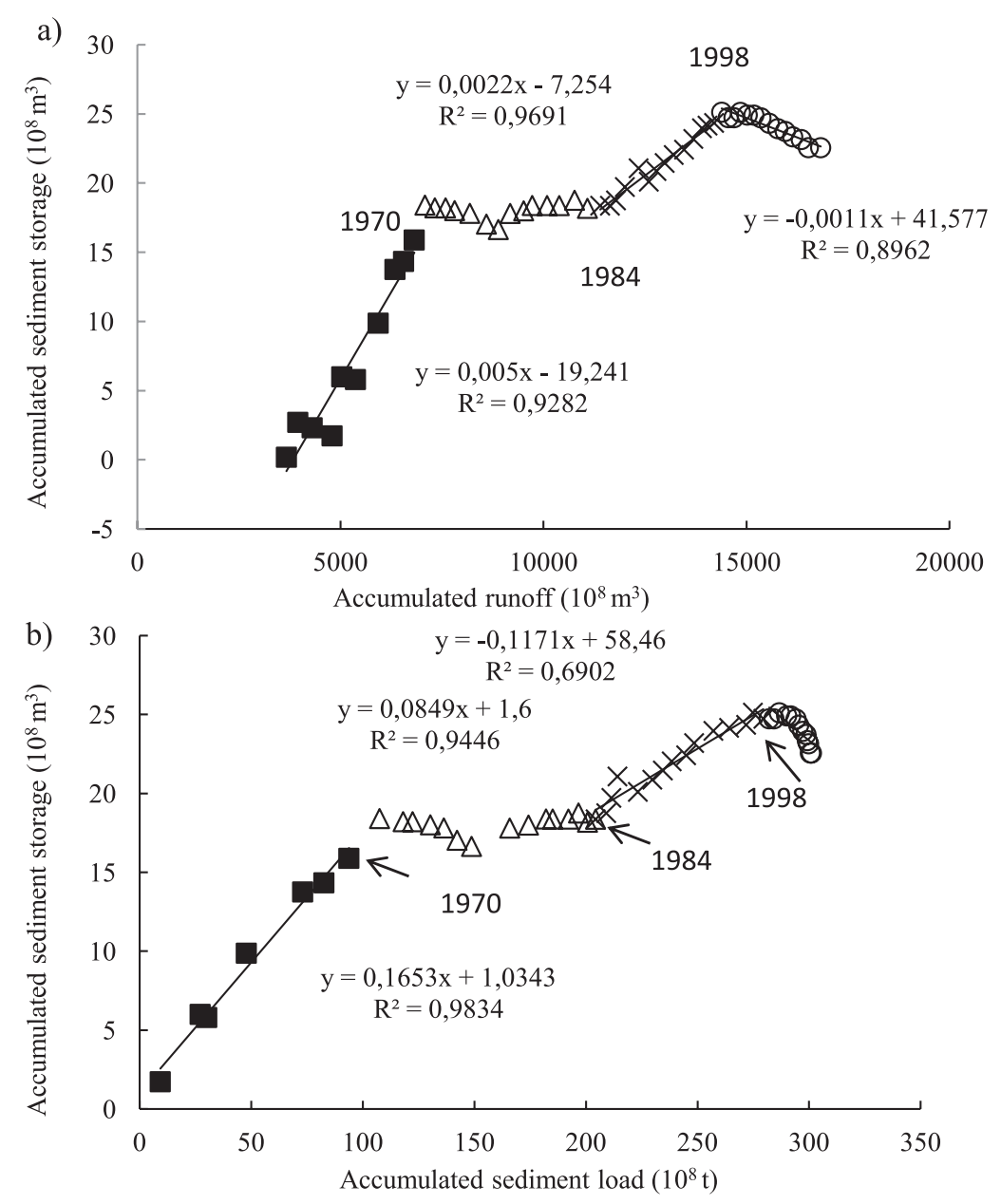

Fig. 3. Relationship between accumulated deposition in the river reach and inputs of river flow and sediment load of the XBGL. 

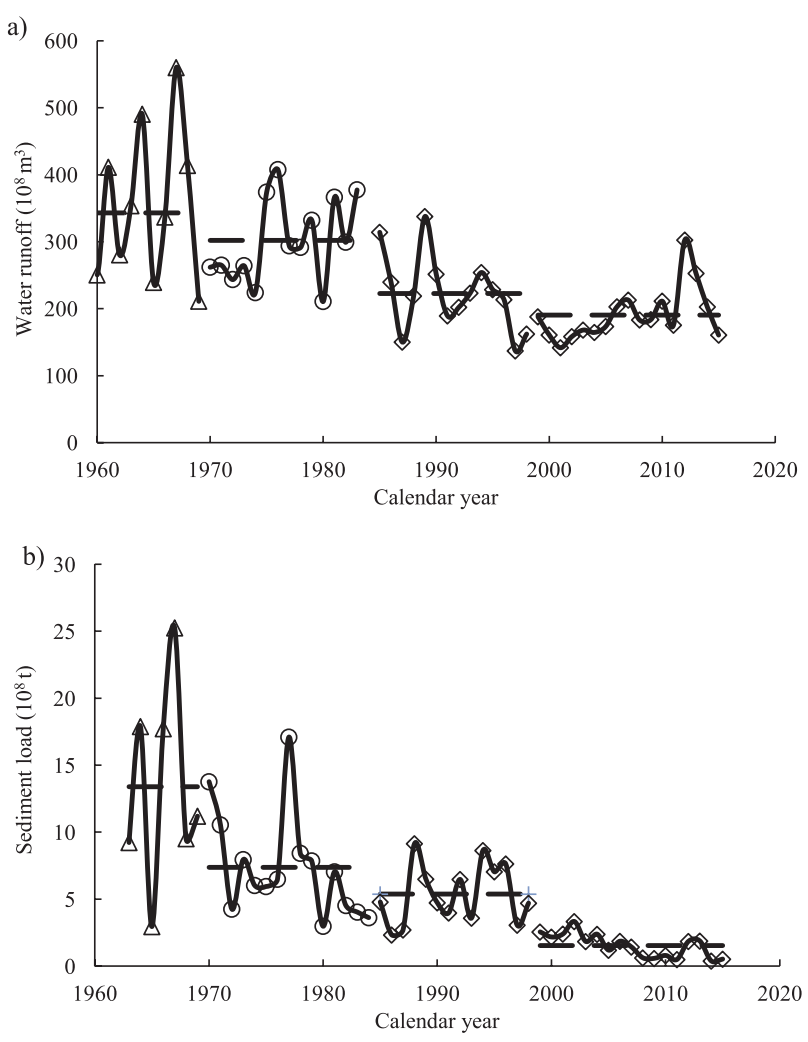

Fig. 4. Water runoff a) and sediment load b) entering the XBGL.

The entire period can be divided into: 1950-1969, 1970-1984, 1985-1998, and after 1999. The fitted equations are as follows:

$\sum\left(\operatorname{Dep}_{S(X B G L)}\right)=0.165 \sum\left(W_{S(X B G L)}\right)+1.034 \quad R^{2}=0.983(1950-1969)$

$\sum\left(\operatorname{Dep}_{S(X B G L)}\right)=0.084 \sum\left(W_{S(X B G L)}\right)+1.6 \quad R^{2}=0.944(1985-1998)$

$\sum\left(\operatorname{Dep}_{S(X B G L)}\right)=-0.117 \sum\left(W_{S(X B G L)}\right)+58.46 \quad R^{2}=0.690 \quad(1999-2011)$

...where $\Sigma\left(D e p_{S(X B G L)}\right)$ is the accumulated deposition in XBGL $\left(10^{8} \mathrm{~m}^{3}\right)$, that is, the accumulated sediment stored in XBGL, and $\Sigma\left(W_{S(X B G L)}\right)$ can be represented as $\Sigma\left(W_{S(L M)}+W_{S(H J)}\right)\left(10^{8} \mathrm{t}\right)$.

$\sum\left(\operatorname{Dep}_{S(X B G L)}\right)=0.005 \sum\left(W_{(X B G L)}\right)-19.24 \quad R^{2}=0.928 \quad(1950-1969)$

$\sum\left(\operatorname{Dep}_{S(X B G L)}\right)=0.002 \sum\left(W_{(X B G L)}\right)-7.254 \quad R^{2}=0.969$ (1985-1998)

$\sum\left(\operatorname{Dep}_{S(X B G L)}\right)=-0.001 \sum\left(W_{(X B G L)}\right)+41.57 R^{2}=0.896 \quad(1999-2011)$

...where $\Sigma\left(W_{(X B G L)}\right)$ can be represented as $\Sigma\left(W_{(L M)}+W_{(H J)}\right)$ $\left(10^{8} \mathrm{~m}^{3}\right)$.

The assumption is that when the amount of SSL or runoff decreases, the relationship during this period remains. The unit of estimated deposition in Eqs. (12) and (13) is $10^{8} \mathrm{~m}^{3}$, and the unit of Eq. (8) is $10^{8} \mathrm{t}$. The porosity used is $1440 \mathrm{~kg} / \mathrm{m}^{3}$.

With different combinations of gradients and intercepts, the effects of change in runoff and SSL on the decrease in deposition vary in different periods. From 1950 to 1969 the annual decrease in runoff smaller than $192 \times 10^{8} \mathrm{~m}^{3}$ led to a decreasement in deposition. From 1985 to 1998 the amount was approximately $259 \times 10^{8} \mathrm{~m}^{3}$. From 1999 to 2011 , too small gradients $(-0.001$ and -0.117$)$ and too large intercepts (58.46 and 41.57) meant an increased deposition for decreased runoff and SSL.

\section{Runoff and Sediment Load Entering XBGL}

The temporal variations in runoff and SSL entering XBGL $\left(W_{(X B G L)}\right.$ and $\left.W_{S(X B G L)}\right)$ are shown in Fig. 4. The runoff and SSL from the TDG-LM drainage area show a dramatic decreasing trend. The average runoff totals in 1950-1969, 1970-1984, 1985-1998, and 1999-2015 are $343 \times 10^{8} \mathrm{~m}^{3}, 301 \times 10^{8} \mathrm{~m}^{3}, 223 \times 10^{8} \mathrm{~m}^{3}$, and $191 \times 10^{8} \mathrm{~m}^{3}$, respectively, and the corresponding decreased ratios compared to former periods are $12 \%, 26 \%$, and $14 \%$, respectively. The average sediment loads in 1950-1969, $1970-1984,1985-1998$, and $1999-2015$ are $13.4 \times 10^{8}$ $\mathrm{t}, 7.4 \times 10^{8} \mathrm{t}, 5.4 \times 10^{8} \mathrm{t}$, and $1.5 \times 10^{8} \mathrm{t}$, respectively, and the corresponding decreased ratios compared to former periods are $44 \%, 27 \%$, and $71 \%$, respectively. The average concentrations during these four periods are $39 \mathrm{~kg} / \mathrm{m}^{3}, 25 \mathrm{~kg} / \mathrm{m}^{3}, 24 \mathrm{~kg} / \mathrm{m}^{3}$, and $7.8 \mathrm{~kg} / \mathrm{m}^{3}$, respectively.

The dramatic declining trends of water and SSL from the middle YR are compound effects of climate change and human activities. Human activities contain engineering and non-engineering measurements in the CSSA [42]. The most important non-engineering measurements are water-soil conservation practices. Engineering measurements include dams and reservoirs. Remote sensing data indicate that the average vegetation coverage on the Loess Plateau increased from 25\% in 1978 to $46 \%$ in 2010 [44]. The influence of human activities on runoff and sediment processes are summarized in Tables 2 and 3 [43, 44]. Annual runoff reduction by water and soil conservation practices in the TDG-HYK drainage area in 1990-1999 was approximately $96 \times 10^{8} \mathrm{~m}^{3} / \mathrm{a}$, and the amount owing to climate change was approximately $75 \times 10^{8} \mathrm{~m}^{3} / \mathrm{a} 2010$ [43]. Increased retention capacity of vegetation, terrace, and dams/reservoirs in 2000-2010 was approximately $0.26 \times 10^{8}$ t/a 2010 [44]. Approximately $57 \%$ of the reduction in average sediment transportation in 19801999 and 2000-2010 resulted from the increased vegetation coverage [44].

The contribution of human activities on runoff and SSL in the TDG-LM drainage area may influence the following analysis; however, different references have different values (Table 4). Notably, the spatial (from TDG to Lijin) and temporal (1950-2015) scales of the objective are large, and certain simplifications are available and necessary. Hence, results of previous research on drainage area (between TDG and LM) and channel (i.e., the XBGL and LYR) are collected. The averaged values of previous results may lead to a median coefficient 
Table 2. Percentages of runoff reduction in the mean annual runoff over the period of 1956-1959 and the proportions of runoff deviations due to climate change, water consumption, and soil erosion control practices in the TDG-HYK drainage area of the Middle YR in different periods [43].

\begin{tabular}{|c|c|c|c|c|c|}
\hline & & $1960-1969$ & $1970-979$ & 1980-1989 & 1990-1999 \\
\hline Ratio of annual runoff & ction to mean annual runoff during 1956-1959 (\%) & -14.2 & -36.6 & -40.1 & -57.7 \\
\hline & Annual runoff reduction $\left(10^{8} \mathrm{~m}^{3} / \mathrm{a}\right)$ & -17.62 & -43.46 & -21.60 & -75.18 \\
\hline Cimiate change & Contribution to the total runoff deviations (\%) & 41.9 & 40.1 & 18.2 & 44.0 \\
\hline Water use and & Annual runoff reduction $\left(10^{8} \mathrm{~m}^{3} / \mathrm{a}\right)$ & -17.33 & -45.96 & -66.08 & -63.99 \\
\hline conservation practices & Contribution to the total runoff deviations (\%) & 41.2 & 42.4 & 55.6 & 37.6 \\
\hline Soil conservation & Annual runoff reduction $\left(10^{8} \mathrm{~m}^{3} / \mathrm{a}\right)$ & -7.11 & -18.92 & -31.27 & -31.71 \\
\hline practices & Contribution to the total runoff deviation (\%) & 16.9 & 17.5 & 26.3 & 18.6 \\
\hline
\end{tabular}

Table 3. Average annual sediment load in the Loess Plateau of the YR and contributions of sediment identity factors between the periods and its drivers [43].

\begin{tabular}{|c|c|c|c|c|}
\hline & & $1951-1979$ & $1980-1999$ & $2000-2010$ \\
\hline \multicolumn{2}{|c|}{ Average annual sediment load in the Loess Plateau reach $\left(10^{8} \mathrm{t} / \mathrm{a}\right)$} & 1.34 & 0.72 & 0.32 \\
\hline \multirow{3}{*}{ Increased retention capacity $\left(10^{8} \mathrm{t} / \mathrm{a}\right)$} & Vegetation & & 0.06 & 0.23 \\
\hline & Terrace & & 0.21 & 0.07 \\
\hline & Dams and reservoirs & & 0.13 & -0.04 \\
\hline \multirow{2}{*}{ Contribution on decrease of sediment flux (\%) } & Water yield capacity & & -1.26 & -3.15 \\
\hline & Sediment concentration & & 0.12 & -1.2 \\
\hline
\end{tabular}

Table 4. Change in runoff and sediment load by human activities in the TDG-LM drainage .

\begin{tabular}{|c|c|c|c|c|}
\hline Periods & & $\begin{array}{l}\text { Runoff } \\
\text { reduction } \\
\left(10^{8} \mathrm{~m}^{3} / \mathrm{a}\right)\end{array}$ & $\begin{array}{c}\text { Reduced } \\
\text { sediment } \\
\text { load } \\
\left(10^{8} \mathrm{t} / \mathrm{a}\right)\end{array}$ & References \\
\hline \multirow{4}{*}{$70 \mathrm{~s}$} & \multirow{4}{*}{$1970-1979$} & 10.962 & 2.11 & [17] \\
\hline & & 3.35 & 1.458 & [12] \\
\hline & & 8.641 & 2.313 & [37] \\
\hline & & 4.54 & 1.99 & [34] \\
\hline \multirow{5}{*}{$80 \mathrm{~s}$} & \multirow{4}{*}{$1980-1989$} & 14.841 & 2.451 & [17] \\
\hline & & 3.521 & 1.398 & [12] \\
\hline & & 9.302 & 2.199 & [37] \\
\hline & & 5.7 & 2.23 & [34] \\
\hline & 1986-1989 & 12.365 & & [38] \\
\hline \multirow{4}{*}{$90 \mathrm{~s}$} & \multirow{3}{*}{$1990-1996$} & 3.993 & 1.688 & [12] \\
\hline & & 10.836 & 2.738 & [37] \\
\hline & & 6.41 & 2.61 & [34] \\
\hline & 1990-1999 & 6.55 & & {$[38]$} \\
\hline \multirow[t]{2}{*}{$\begin{array}{c}21^{\text {st }} \\
\text { century }\end{array}$} & $2000-2010$ & 9.799 & & {$[38]$} \\
\hline & $1975-2012$ & & 4.73 & [39] \\
\hline
\end{tabular}

in describing the relationship, and uncertainties may be caused by the averaging treatment and simplifications of adopted equations in each segment. The average values estimated with hydrologic methods or water-soil conservation methods are adopted. The availability of this assumption is discussed in a later section.

The annual average change of runoff and SSL $\left(\Delta W_{(L M)}\right.$ and $\left.\Delta W_{S(L M)}\right)$ in the four periods are shown in Fig. 5. The amounts of reduced runoff in 1980-1989 and 2000-2010 at $9.15 \times 10^{8} \mathrm{~m}^{3} / \mathrm{a}$ and $9.8 \times 10^{8} \mathrm{~m}^{3} / \mathrm{a}$, respectively, are relatively larger than those in 1970-1979 and 1990-1999 at $6.87 \times 10^{8} \mathrm{~m}^{3} / \mathrm{a}$ and $6.95 \times 10^{8} \mathrm{~m}^{3} / \mathrm{a}$, respectively. However, the amount of reduced sediment load in 1980-1989 $\left(2.07 \times 10^{8} \mathrm{t} / \mathrm{a}\right)$ is almost equal to those in $1970-1979\left(1.97 \times 10^{8} \mathrm{t} / \mathrm{a}\right)$ and 1990-1999 $\left(2.35 \times 10^{8} \mathrm{t} / \mathrm{a}\right)$. The average concentrations in 1970-1979, 1980-1989, 1990-1999, and 2000-2010 are approximately 286, 226, 338, and $483 \mathrm{~kg} / \mathrm{m}^{3}$, respectively. This finding indicates that, compared with the other three periods, the change in runoff is relatively large while the change in SSL is relatively small, and the corresponding average concentration is the smallest in 1980-1989. The maximum average concentration among the four periods occurred in 2000-2010, with a large amount of trapped SSL. 


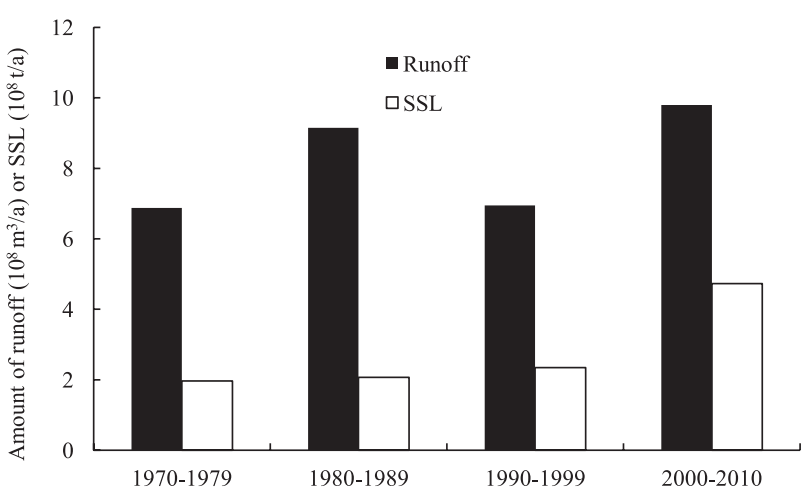

Fig. 5. Average contribution of human activities on runoff and sediment load.

According to the previous periods (1971-1984, 1985-1998, and 1999-2012), the influence of human activities on the change in runoff and SSL in the TDG-LM drainage area on XBGL can easily be estimated $\left(\Delta W_{(X B G L)}\right.$ and $\left.\Delta W_{S(X B G L)}\right)$, as shown in Fig. 6. The runoff $\left(\Delta W_{(X B G L)}\right)$ in 1999-2012 increased approximately $24.7 \%$ compared with those in 1971-1984 and 1985-1998. The sediment load $\left(\Delta W_{S(X B G L}\right)$ in 1999-2012 also increased approximately $28.6 \%$ compared with those in 1971-1984 and 1985-1998. The average concentrations in change of inflow are $261 \mathrm{~kg} / \mathrm{m}^{3}$ in $1971-1984,291 \mathrm{~kg} / \mathrm{m}^{3}$ in $1985-1998$, and $475 \mathrm{~kg} / \mathrm{m}^{3}$ in $1999-2012$.
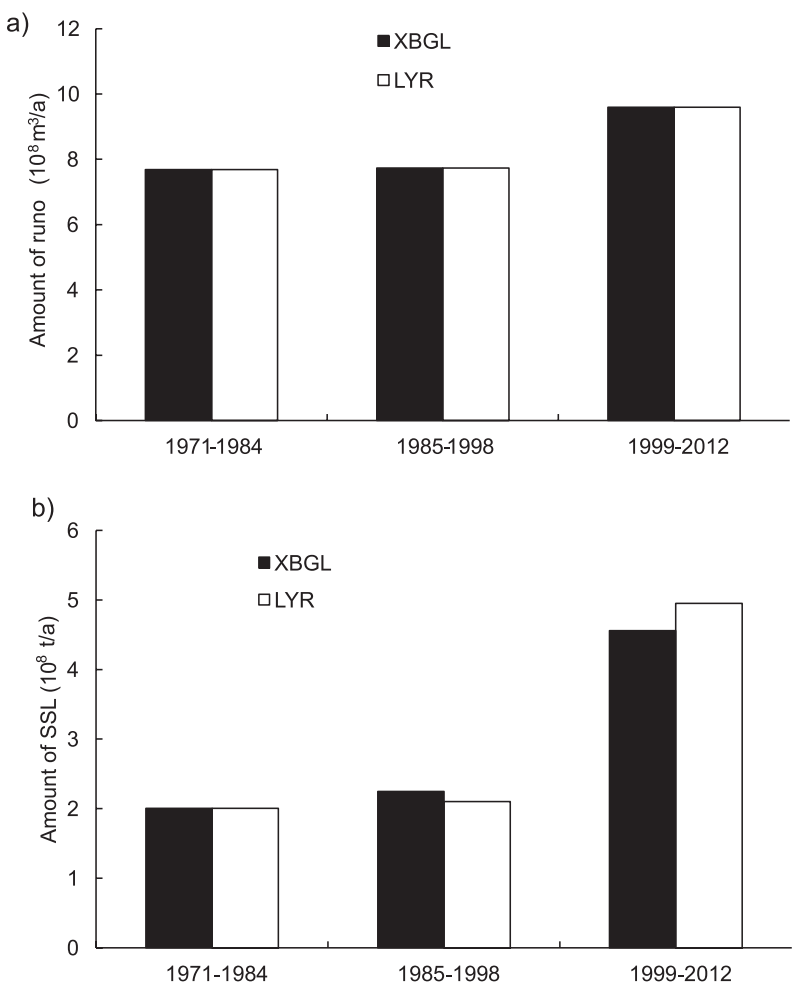

Fig. 6. Temporal variation of reduced runoff a) and sediment load b) entering the XBGL and LYR.

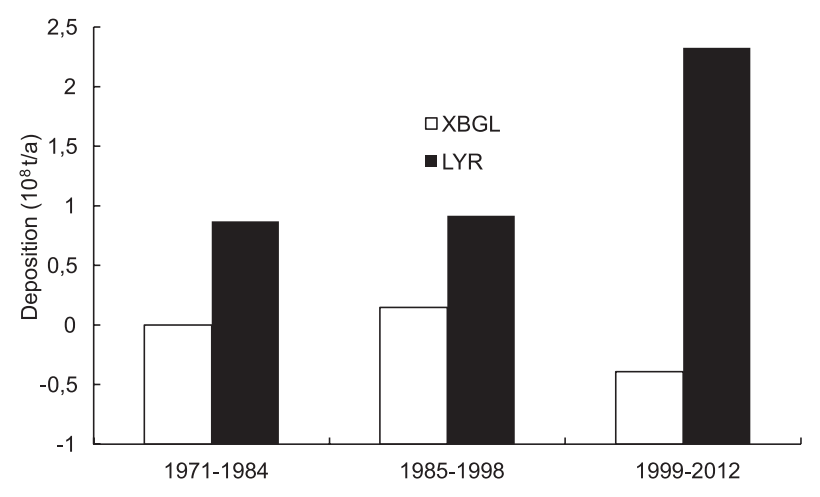

Fig. 7. Change of deposition in the XBGL and LYR.

\section{Deposition in XBGL}

According to Eqs. (12) and (13), the effects of change in runoff and SSL by human activities $\left(\Delta W_{(X B G L)}\right.$ and $\left.\Delta W_{S(X B G L)}\right)$ on deposition in XBGL $\left(\Delta D e p_{S(X B G L)}\right)$ can be estimated. The ratios between $\triangle D e p_{S(X B G L)}$ and inflow at LM station $\left(\Delta W_{S(L M)}\right.$ and $\left.\Delta W_{(L M}\right)$ are 0 in 1971-1984, 0.15 in 1985-1998, and -0.39 in 1999-2012. From 1985 to 1998 , accumulated deposition in XBGL is positively correlated with accumulated inflow, but the intercepts of fitted equations are different (Fig. 3). Hence, from 1985 to 1998 , decreased SSL by human activities led to decreased deposition, the same as decreased runoff by human activities. As a compound effect of the change in runoff and SSL, the decrease in runoff and SSL in XBGL from 1985 to 1998 result in decreased deposition. However, the correlations between accumulated deposition in XBGL and accumulated inflow in 1999-2010 are negative gradients with large intercepts (58.46 and 41.57 for SSL and runoff, respectively). The decrease in runoff and SSL led to increased deposition in 1999-2010.

\section{Deposition in LYR}

The reduced amounts of runoff entering the LYR $\left(\Delta W_{(3)}\right)$ are the same as those of XBGL (Fig. 6a) on the basis of previous assumptions for simplicity (Eq. 7). Compared with the decreased in SSL $\left(\Delta W_{S(X B G L)}\right)$ in XBGL (Fig. 6b), the amounts in the lower channel $\left(\Delta W_{S(3)}\right)$ before 1984 are the same. In 1985-1998 the change in SSL entering the LYR decreased by approximately $7 \%$ compared with that of XBGL. After 1999, the change in SSL entering the LYR increased by approximately $9 \%$ compared with that of XBGL.

After sediment storage of XBGL, the trend in changed deposition in the LYR $\left(\Delta D e p_{S(3)}\right)$ varies. In 1971-1984, the ratio between $\Delta D e p_{S(3)}$ and inflow at LM station $\left(\Delta W_{S(L M)}\right.$ and $\left.\Delta W_{(L M)}\right)$ in the LYR is 0.87. Ran $[12,13]$ analyzed the effects of human activities in the Wei River Basin (WRB) on the LYR. The relationship between deposition in the LYR and change in runoff and SSL were simplified as constant coefficients. The relationship between $D e p_{S(3)}$ and runoff change in 
WRB used was 20, and the relationship between $D e p_{S(3)}$ and sediment load change in WRB was 0.7. Based on these coefficients, the water and sediment reduced by water-sediment conservation practices in the CSSA led to decreased deposition of $1.57 \times 10^{8} \mathrm{t}$ and decreased runoff of $45 \times 10^{8} \mathrm{~m}^{3}$ [12]. The coefficient 0.7 used in $\operatorname{Ran}[12,13]$ can also verify the availability of average value adopted in Fig. 5. The relationship in 1985-1998 represented by the constant of 0.92 is almost the same as that in 1971-1984 with a constant value of 0.87 ; however, this changed dramatically after 1999.

The relationship between human activities in the middle area and change in runoff and SSL in the lower channel changed after 1999. For XBGL, human activities in the upland may trap runoff and sediment load with different concentrations, $260 \mathrm{~kg} / \mathrm{m}^{3}$ in 1971-1984, $291 \mathrm{~kg} / \mathrm{m}^{3}$ in $1985-1998$, and $479 \mathrm{~kg} / \mathrm{m}^{3}$ in $1999-2012$. After sediment storage in the wide and shallow channel of XBGL, it lead to a series decrease in deposition in the LYR as negative and positive coefficients for runoff and SLL, respectively. However, other factors, such as low sediment-laden flow from tributaries, water consumption along the lower channel, and operation of the two larger reservoirs alleviated the potential increase in deposition.

\section{Discussion}

The relationship between human activities in the TDG-LM drainage area and deposition in the LYR is affected by various uncertainties. The first uncertainty is caused by different relationships established in previous research that were adopted in the analysis, including different contribution ratios of human activities on the change of runoff and SSL and different relationships between deposition in the river reach and inflow condition. The second uncertainty consists of simplifications and assumptions, including the treatment of five tributaries (the Fen, Wei, Beiluo, Qin, and Yiluo rivers), the two reservoirs (the Sanmenxia and Xiaolangdi), and diverted water and trapped sediment load along XBGL and LYR. The uncertainties caused by water and sediment diversion will not be discussed here, as water diversion seems to be an uncontrollable influence.

\section{Contribution Ratios of Human Activities in the Middle YR}

The contribution ratios of human activities in the CSSA on the change in runoff and SSL vary by different

Table 5. Contribution ratios of human activities and climate change on runoff reduction.

\begin{tabular}{|c|c|c|c|c|c|}
\hline \multirow{2}{*}{ Study area } & \multicolumn{2}{|c|}{ Data } & \multirow{2}{*}{ Human activities (\%) } & \multirow{2}{*}{ Climate change $(\%)$} & \multirow{2}{*}{ Reference } \\
\hline & Benchmark & Changed period & & & \\
\hline YRB & \multicolumn{2}{|c|}{$1970-2008$} & 83.0 & 17.0 & {$[28]$} \\
\hline YRB & \multicolumn{2}{|c|}{$2000-2008$} & 55.0 & 45.0 & [29] \\
\hline YRB & 1919-1986 & $2000-2012$ & 43.4 & 56.6 & {$[31]$} \\
\hline YRB & \multicolumn{2}{|c|}{$1951-2010$} & 76 & 24 & {$[27]$} \\
\hline YRB & $1950-1979$ & 1980-1989 & 46.6 & 53.4 & {$[32]$} \\
\hline TDG-HYK & \multicolumn{2}{|c|}{$1990-2000$} & 57.0 & 43.0 & {$[33]$} \\
\hline TDG-HYK & \multicolumn{2}{|c|}{$1997-2006$} & 76.5 & 23.5 & {$[30]$} \\
\hline TDG-HYK & Before 1985 & $1986-2008$ & 72.0 & 28.0 & {$[34]$} \\
\hline
\end{tabular}

Table 6. Contribution ratios of human activities and climate change on SSL reduction.

\begin{tabular}{|c|c|c|c|c|c|}
\hline \multirow{2}{*}{ Study area } & \multicolumn{2}{|c|}{ Data } & $\begin{array}{c}\text { Human activities } \\
(\%)\end{array}$ & Climate change (\%) & Reference \\
\cline { 2 - 6 } & Benchmark & Changed period & 70 & 30 & {$[27]$} \\
\hline YRB & \multicolumn{2}{|c|}{$2000-2008$} & 54.0 & 46.0 & {$[29]$} \\
\hline YRB & \multicolumn{2}{|c|}{$1979-2008$} & 81.0 & 19.0 & {$[35]$} \\
\hline YRB & \multicolumn{2}{|c|}{$2000-2012$} & $72.2-76.5$ & 28.1 & {$[31]$} \\
\hline YRB & $1919-1986$ & 71.9 & 13.2 & {$[32]$} \\
\hline YRB & \multicolumn{2}{|c|}{$1980-1989$} & 86.8 & 44.6 & {$[34]$} \\
\hline TDG-HYK & Before 2005 & $1986-2008$ & 55.4 & 50.3 & {$[36]$} \\
\hline TDG-LM & $1980-2006$ & 49.7 & & {$[30]$} \\
\hline TDG-HYK & $1997-2009$ & & & \\
\hline
\end{tabular}


researchers, as listed in Tables 5 and 6. The contribution ratios for human activities on runoff range from $43.4 \%$ to $83 \%$, and the average ratio is $63.7 \%$. The contribution ratios on SSL vary from $49.7 \%$ to $86.6 \%$, and the average ratio is $67.1 \%$. This difference may be caused by different objective drainage areas, benchmark periods, and periods of interest. The different contribution ratios of human activities may lead to varying changes in runoff and SSL by human activities, values in Table 4, and estimated data in Fig. 5. These uncertainties may lead to quantitative difference but may not change the qualitative trend.

Water-soil conservation practices are primarily human activities. For the water-soil conservation measures in the middle YR basin, the practice area shows an increasing trend, except for 1990-1996 (Fig. 8). The practice area before 1959 was only $3 \times 10^{3} \mathrm{~km}^{2}$, and the area in 1990-1996 was approximately $16.5 \times 10^{3} \mathrm{~km}^{2}$. Annual practice area after 1997 is the largest at $3.5 \times 10^{3} \mathrm{~km}^{2} / \mathrm{a}$. The practice areas in 1950-1970, $1971-1984,1985-1998$, and $1999-2006$ are $14.8 \times 10^{3} \mathrm{~km}^{2}$, $29 \times 10^{3} \mathrm{~km}^{2}, 41.2 \times 10^{3} \mathrm{~km}^{2}$, and $28.9 \times 10^{3} \mathrm{~km}^{2}$, respectively. The practice areas in 1971-1984 and 1999-2006 are almost the same, while the change in runoff and SSL entering XBGL are different probably because of the different effects of grass, farmland, and other factors.

\section{Relationships between Deposition and Inflow}

For XBGL, the relationship in the fourth period (1999-2011) depicts small values of $R^{2}$, and the corresponding coefficients fitted in Eqs. (6) and (7) may lead to uncertainties. However, the continuous deposition in XBGL and decrease in trend of runoff and SSL can be certified.

Based on data in 1950-1997, the deposition during flood season in the LYR can be estimated with runoff and SSL measured at Sanmenxia Station, as well as the HSG and XD stations, as shown in [21]:

$$
\operatorname{Dep}_{S(3)}{ }^{\prime}=a_{2} W_{S(3)}{ }^{\prime}-b_{2} W_{(3)}{ }^{\prime}+c_{2}
$$

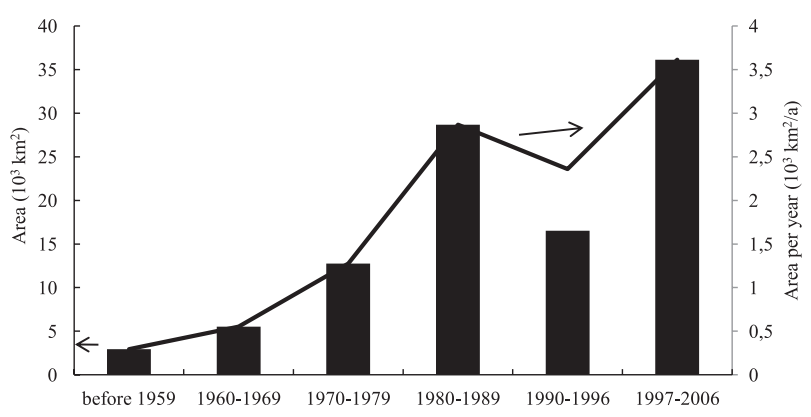

Fig. 8. Water-soil conservation practices in the middle of the YR basin. ...where $\operatorname{Dep}_{S(3)}{ }^{\prime}$ is the deposition during flood season in the Tiexie-Lijin reach $\left(10^{8} \mathrm{t}\right)$; and $W_{(3)}^{\prime}$ and $W_{S(3)}{ }^{\prime}$ are the total runoff $\left(10^{8} \mathrm{~m}^{3}\right)$ and SSL $\left(10^{8} \mathrm{t}\right)$ during flood season in the LYR (by summing up data at Sanmenxia, HSG, and XD stations). The subscript 3 represents the LYR. The values of $a_{2}, b_{2}$, and $c_{2}$ are $0.523,0.025$, and 2.352 , respectively. The sum of river flow or sediment at Sanmenxia, HSG, and XD stations is also adopted to represent the inputs of water and sediment in the LYR in [10]. The coefficients in Eq. (14) are different from those in Eqs. (10) and (11), which indicate the influence of runoff and SSL in the non-flood season.

Runoff data measured at TDG station $\left(W_{(T)}\right)$ and SSL eroded from the TDG-LM drainage area $\left(W_{S(T-L)}\right)$ can also be adopted to estimate annual deposition and deposition during flood season in the LYR. The equations are expressed as [11]:

$$
\begin{aligned}
& \operatorname{Dep}_{S(3)}=0.839 W_{S(T-L)}-0.398 W_{(T)} \\
& D e p_{S(3)}{ }^{\prime}=0.887 W_{S(T-L)}{ }^{\prime}-0.130 W_{(T)}{ }^{\prime}
\end{aligned}
$$

...where $D e p_{S(3)}$ ' and $\operatorname{Dep}_{S(3)}$ are the deposition during flood season and annual deposition in the Sanmenxia-Lijin reach $\left(10^{4} \mathrm{t}\right) ; W_{(T)}{ }^{\prime}$ and $W_{(T)}$ are the runoff from the drainage area upper TDG $\left(10^{8} \mathrm{~m}^{3}\right)$; and $W_{S(T-L)}$ ' and $W_{S(T-L)}$ are the SSLs from the TDG-LM drainage area $\left(10^{4} \mathrm{t}\right)$. The differences in the coefficients of the second term $\left(W_{(T)}{ }^{\prime}\right.$ and $\left.W_{(T)}\right)$ on the RHS of Eqs. (15) and (16) indicate the influence of runoff from the upper YR during non-flood season on the deposition in LYR. In investigating the relationship between the deposition in LYR and the change in runoff and SSL by conservation practices in the middle YR, the second terms on the RHS of Eqs. (15) and (16) may be constant. The relationship between the SSL from the middle YR and the deposition in the LYR are 0.839 (annual) and 0.887 (flood season), respectively. However, the decadal trend of deposition changed in the LYR may not be changed.

Runoff and SSL data measured at the LM station, as well as the HJ, HX, ZT, HSG, and XD stations for the five tributaries, may also be used and are expressed as [22] follows:

$$
\begin{gathered}
W_{S, 6}-W_{S, L J}=207 \frac{W_{S, L M}}{W_{L M}}+7 \frac{W_{S, H J}}{W_{H J}}+9 \frac{W_{S, Z T}}{W_{Z T}} \\
-3 \frac{W_{S, H X}}{W_{H X}}-277 \frac{W_{S, X D}}{W_{X D}}-128 \frac{W_{S, H S G}}{W_{H S G}}
\end{gathered}
$$

...where $W_{\mathrm{s}}$ and $W$ are runoff $\left(10^{8} \mathrm{t} / \mathrm{a}\right)$ and $\operatorname{SSL}\left(10^{8} \mathrm{~m}^{3} / \mathrm{a}\right)$; the subscript 6 represents the total incoming runoff in the LYR (LM, HJ, ZT, HX, XD, and HSG station); and the subscript $L J$ represents the controlling station of Lijin. The left-hand side items of Eq. (17) represent the deposited sediment in the river reach of LM-Lijin, and the RHS items of Eq. (17) represents the contributions by inflow from the stem channel (LM) and tributaries (HJ, ZT, HX, XD, and HSG stations). 
The relationship between sediment reduction in the upland and deposition in the LYR is also simplified as a constant coefficient in some cases [12, 13]. Different fitted coefficients or empirical formula used in the XBGL and LYR may lead to different quantitative results, while the qualitative trend may not change.

\section{Xiaolangdi and Sanmenxia Reservoirs}

Sanmenxia (SMX) and Xiaolangdi (XLD) reservoirs are located in the LYR. The operation of SMX Reservoir began in 1960, and serious deposition occurred after its operation [11]. From 1960 to 1973, reservoir storage volume decreased dramatically as the storage volume at an elevation of $320 \mathrm{~m}$ decreased from $24 \times 10^{8} \mathrm{~m}^{3}$ to approximately $8 \times 10^{8} \mathrm{~m}^{3}$ [11]. The deposition was then limited after 1973. In total, the storage volume at an elevation of $230 \mathrm{~m}$ decreased from $8 \times 10^{8} \mathrm{~m}^{3}$ to $4 \times 10^{8} \mathrm{~m}^{3}$ from 1973 to 2002 [11].

The XLD dam is located at the mouth of the final gorges in the middle reach of the YR, which is $130 \mathrm{~km}$ downstream of the SMX dam and upstream of the XLD station. The XLD Multipurpose Dam Project was approved in April 1991, and it has stored water since October 1999. The XLD reservoir represents more than 90 percent of the whole YR basin. Its total capacity is $12.65 \times 10^{9} \mathrm{~m}^{3}$, which is composed of approximately $60 \%$ sediment storage and approximately $40 \%$ flow regulation and electricity generation. The storage volume of the XLD reservoir at an elevation of $240 \mathrm{~m}$ decreased from $56 \times 10^{8} \mathrm{~m}^{3}$ to about $52 \times 10^{8} \mathrm{~m}^{3}$ [45, 46]. After the operation of the XLD reservoir in 2000 for power generation, the LYR management held joint operations of the SMX and XLD reservoir constructed by YRCC. The joint operation was called a watersediment regulation scheme, which started in 2002. With 13 joint operations from 2002 to 2011, approximately $50.91 \times 10^{9} \mathrm{~m}^{3}$ water has been released, and approximately $3.9 \times 10^{8}$ t siltation has been carried and transported into the ocean. After the joint operation in 2002 , the storage volume decreased dramatically from $52 \times 10^{8} \mathrm{~m}^{3}$ to approximately $35 \times 10^{8} \mathrm{~m}^{3}$ at an elevation of $240 \mathrm{~m}$.

During the regulation period (summer season), deposition in the XLD Reservoir may be eroded by large floods. Released floods can maintain certain discharge in the LYR, transport as much SSL to the sea as possible, and reduce reservoir siltation. These may efficiently mitigate the severe aggradation in the LYR. Although the relationship between human activities in the middle YR and deposition in the LYR is idealized, it does reveal the importance of sediment storage in XBGL.

\section{Influence of Tributaries}

Two tributaries are in the LYR, namely, the Yiluo and Qin rivers. The annual mean runoff and SSL of the Yiluo River are approximately $42.93 \times 10^{8} \mathrm{~m}^{3}$ and $4.43 \times 10^{4} \mathrm{t}$, respectively. The annual average runoff and sediment load of the Qin River are approximately $11.2 \times 10^{8} \mathrm{~m}^{3}$ and $5.04 \times 10^{4} \mathrm{t}$, respectively. The corresponding mean concentrations of these two tributaries are very small. Therefore, almost no sediment supplement by tributaries inflow along the lower reach occurs, and it benefits sediment transportation in the LYR.

\section{Conclusions}

Human activities in the TDG-LM drainage area may influence the river reach underneath, including the LM station, XBGL, and LYR. However, sediment deposition in XBGL has changed dramatically since 2000. As the connection of the upland area with series erosion and lower channel with serious deposition changed, the relationship between upland and the lower channel changed accordingly. The contribution of human activities in the TDG-LM drainage area on the LYR is analyzed based on previous research results. Several conclusions can be drawn:

1) Deposition in XBGL was positively correlated with inflow sediment and runoff before 1970. The river reach was in quasi-equilibrium state from 1971 to 1984. After 1985, these variables were positively correlated with a smaller slope. Finally, the correlation became negative after 1999.

2) The ratios between deposition in the XBGL $\left(\triangle D e p_{S(X B G L)}\right)$ and inflow at LM station $\left(\Delta W_{S(L M)}\right.$ and $\left.\Delta W_{(L M)}\right)$ are $0,0.15$, and -0.39 in the periods 1971-1987, 1971-1984, and 1985-1998, respectively.

3) After the fluvial processes of sediment-laden flow running through XBGL, the ratios between deposition in the LYR $\left(\Delta D e p_{S(3)}\right)$ and inflow at LM station $\left(\Delta W_{S(L M)}\right.$ and $\left.\Delta W_{(L M)}\right)$ are 0.87 and 0.92 during the periods 1971-1984 and 1985-1998, respectively. After 1999, the ratio changed dramatically to 2.33.

4) After 1999, as the effect of sediment storage of XBGL changed, the inflow SSL of XBGL decreased $\left(4.6 \times 10^{8} \mathrm{~m}^{3} / \mathrm{a}\right)$ with human activities in the TDG-LM area, while the outflow of the river reach may increase $\left(4.95 \times 10^{8} \mathrm{~m}^{3} / \mathrm{a}\right)$.

\section{Acknowledgements}

This work was supported by the National Science and Technology Support Program (Nos. 2016YFC0402503 and 2012BAB02B02), the National Natural Science Foundation of China (Nos. 51579230 and 51109198), and the National Program on Key Basic Research Projects (No. 2011CB403305).

\section{Conflict of Interest}

The authors declare no conflict of interest. 


\section{References}

1. GAO P., MU X.M., WANG F., LI R. Changes in streamflow and sediment discharge and the response to human activities in the middle reaches of the Yellow River. Hydrol. Earth Syst. Sci. Discuss, 7, 6793, 2010.

2. JIAO J.Y., WANG Z.J., ZHAO G.J., WANG W.Z., MU X.M. Changes in sediment discharge in a sediment-rich region of the Yellow River from 1955 to 2010: implications for further soil erosion control. J Arid Land, 6 (5), 540, 2014.

3. LI B., LI C.Y., LIU J.Y., ZHANG Q., DUAN L.M. Decreased streamflow in the Yellow River Basin, China: Climate change or human-induced ? Water. 9, 116, doi: 10.3390/w9020116, 2017.

4. ZHANG J.J., ZHANG X.P., LI R., CHEN L.L., LIN P.F. Did streamflow or suspended sediment concentration changes reduce sediment load in the middle reaches of the Yellow River ? Journal of Hydrology. 546, 357, 2017.

5. WEI Y.H., JIAN J.Y., ZHAO G.J., ZHAO H.K., HE Z., MU X.M. Spatial-temporal variation and periodic change in streamflow and suspended sediment discharge along the mainstream of the Yellow River duing 1950-2013. Catena, 140, 105, 2016.

6. MIAO C.Y., NI J.R., BORTHWICK A.G.L. Recent changes of water discharge and sediment load in the Yellow River Basin, China. Prog Phys Geogr. 34, 541, 2010.

7. GAO Z.L., FU Y.L., LI Y.H., LIU J.X., CHEN N., ZHANG X.P. Trends of streamflow, sediment load and their dynamic relation for the catchments in the middle reaches of the Yellow River over the past five decades. Hydrology and Earth System Sciences. 16, 3219, 2012.

8. REN M.E. Sediment discharge of the Yellow River, China: past, present and future- A synthesis. Acta Oceanol. Sin. 34 (2), 1, 2015.

9. ZHENG S., WU B.S. Simulation of sedimentation processes of the Xiaobeiganliu reach of the Yellow River and the Lower Wei River. Shuili Xuebao, 45 (2), 150, 2014. [In Chinese with English abstract].

10. XU J.X. Effect of human activities on overall trend of sedimentation in the Lower Yellow River, China. Environmental Management, 33 (5), 637, 2004.

11. XU J.X. Sedimentation and sediment transport in Lower Yellow River as influenced by coupling of water and sediment yield in upper drainage basin. Journal of Sediment Research, 3, 49, 2011 [In Chinese with English abstract].

12. RAN D.C. Water and sediment variation and ecological protection measures in the middle reach of the Yellow River. Resour. Sci, 28, 93, 2006 [In Chinese with English abstract].

13. RAN D.C., LIU B., WANG H. Analysis on sediment reduction of the Yellow River through soil and water conservation measures. SWCC, 10, 35, 2002 [In Chinese with English abstract].

14. GAO P., DENG J.C., CHAI X.K., MU X.M., ZHAO G.J., SHAO H.B., SUN W.Y. Dynamic sediment discharges in the Hekou-Longmen region of Yellow River and soil and water conservation implications. Science of the Total Environment, 578, 56, 2017.

15. GAO P. Stream flow and sediment discharge change trend and its response to human activities in the Middle Yellow River. Shanxi, Institute of Soil and Water Conservation, Chinese Academy of Sciences, 2010 [In Chinese].
16. WANG H.J., YANG Z.S., SAITO Y., LIU J.P., SUN X.X., WANG Y. Stepwise decreases of the Huanghe (Yellow River) sediment load (1950-2005): impacts of climate change and human activities. Glob Planet Change, 57, 331, 2007.

17. RAN D.C., LIU L.W., ZHAO L.Y. Soil and water conservation and water sediment change of drainage area between Hekouzhen and Longmen, the Middle Yellow River Basin. Zhengzhou: The Yellow River Water Conservancy Press, 2000 [In Chinese].

18. HE L., WANG G.Q., LI T.J. Catchment division of the water and sediment yield system and drainage network codification of the key region in the middle Yellow River Basin. Journal of Sediment Research, 2, 39, 2009 [In Chinese with English Abstract].

19. DENG A.J., GUO Q.C, CHEN J.G. Study of evolution of erosion and deposition in Xiaobeiganliu reach of Yellow River. Journal of Sediment Research, 2, 27, 2011 [Iin Chinese with English Abstract].

20. CHEN X.D. The Yellow River Hydrology. Yellow River Conservancy Press, Zhengzhou, China, 1996 [In Chinese].

21. WU B.S., ZHANG Y.F., SHEN G.Q. Water and sediment conditions for the main channel of the Yellow River. The Yellow River Water Conservancy Press: Zhengzhou, China, 2010.

22. HE X.H., GAO Y.J., LI X.Y., XU J.H. Sedimentation impacts of incoming sediment from different areas of the middle reaches of the Yellow River on Sanmenxia Reservoir and its downstream area. Bulletin of Soil and Water Conservation, 28 (6), 86, 2008.

23. CHANG J.X., LI Y.Y., WEI J., WANG Y.M., GUO A.J. Dynamic changes of sediment load and water discharge in the Weihe River, China. Environ Earth Sci., 75, 1042, 2016.

24. ZHANG X.C., PAN Y.M. Investigation and Assessment of Water Resources in the Yellow River. Publishing House of Yellow River Water Conservancy: Zhengzhou, China, 50, 2006 [In Chinese with English Abstract].

25. KUANG J., ZHANG X.C. Yellow River water resources and the concerned series consistency processing. Journal of China Hydrology, 26 (6), 6, 2006 [In Chinese with English abstract].

26. DU J., SHI C.X. Effects of climatic factors and human activities on runoff of the Weihe River in recent decades. Quaternary International, 282, 58, 2012.

27. WANG Z.Y., WU B.S., WANG G.Q. Fluvial processes and morphological response in the Yellow and Weihe Rivers to closure and operation of Sanmenxia Dam. Geomorphology, 91, 65, 2007.

28. WANG Y., DING Y.J., YE B.S., LIU F.J., WANG J., WANG J. Contributions of climate and human activities to changes in runoff of the Yellow and Yangtze rivers from 1950 to 2008. Sci. China Earth Sci., 56 (8), 1398, 2013.

29. MIAO C., NI, J., BORTHWICK A.G.L., YANG L. A preliminary estimate of human and natural contributions to the changes in water discharge and sediment load in the Yellow River. Glob. Planet. Chang, 76 (3-4), 196, 2011.

30. YAO W.Y., RAN D.C., CHEN J.N. Recent changes in runoff and sediment regimes and future projections in the Yellow River Basin. Adv. Water Sci, 24, 607, 2013 [In Chinese with English Abstract].

31. YAO W.Y., XIAO P.Q., SHEN Z.Z., WANG J.H., JIAO P. Analysis of the contribution of multiple factors to the recent decrease in discharge and sediment yield 
in the Yellow River Basin, China. J. Geogr. Sci, 26 (9), 1289, 2016

32. CHU C.J., LI Y.L. Variation of runoff and sediment and their driving factors of the Yellow River Mainstream in the past 60 Years. Journal of Soil and Water Conservation, 27 (5), 41, 132, 2013 [In Chinese with English Abstract].

33. LIU C.M., ZHANG X.C. Causal analysis on actual water flow reduction in the mainstream of the Yellow River. Acta Geograph. Sin, 59, 323, 2004 [In Chinese].

34. GAO P., MU X.M., WANG F., LI R. Changes in streamflow and sediment discharge and the response to human activities in the middle reaches of the Yellow River. Hydrol. Earth Syst. Sci, 15 (1), 1, 2011.

35. MU X.M. Dynamic changes of sediment discharge and the influencing factors in the Yellow River, China, for the recent 90 years. Clean: Soil, Air, Water, 40 (3), 303, 2012.

36. YUE X., MU X., ZHAO G., SHAO H., GAO P. Dynamic changes of sediment load in the middle reaches of the Yellow River Basin, China and implications for ecorestoration. Ecol. Eng, 73, 64, 2014.

37. MU X.M., ZHANG L., MC VICAR T.R., CHILLE B., GAU P. Analysis of the impact of conservation measures on stream flow regime in catchments of the Loess Plateau, China. Hydrol. Processes, 21 (16), 2124, 2007.

38. LI E.H., MU X.M., ZHAO G.J. Temporal changes in annual runoff and influential factors in the upper and middle reaches of Yellow River from 19192010. Advances in Water Sciences, 25 (2), 155, 2014.

39. OUYANG C.B., WANG W.L., TIAN Y., TIAN S.M. Evaluation on the variation of water-sediment and human activities in the He-Long Reach of the Yellow River over the past 60 years. Journal of Sediment Research, 4, 55, 2016.

40. SEARCY J.K., HARDISONI C.H., LANGBEIN W.B. Double mass curves, Geological Survey Water Supply Paper, 1541-B; US Geological Survey: Washington, SC, USA, 1960.

41. WALLING D.E. Human impact on land-ocean sediment transfer by the world's rivers. Geomorphology, 79 (3-4), 192, 2006.

42. RUSTOMJI P., ZHANG X.P., HAIRSINE P.B., ZHANG L., ZHAO J. River sediment load and concentration responses to changes in hydrology and catchment management in the Loess Plateau region of China. Water Resources Research, 44, W00A04, doi:10.1029/2007WR006656, 2008.

43. SHI C.X., ZHOU Y.Y., FAN X.L., SHAO W.W. A study on the annual runoff change and its relationship with water and soil conservation practices and climate change in the middle Yellow River basin. Catena, 100, 31, 2012.

44. WANG S., FU B.J., PIAO S.L., LU Y.H., CIASI P., FENG X.M., WANG Y.F. Reduced sediment transport in the Yellow River due to anthropogenic changes. Natural Geosciences, 2015. DOI: 10.1038/NGEO2602

45. ZHAO G.J., TIAN P., MU X.M. Quantifying the impact of climate variability and human activities on streamflow in the middle reaches of the Yellow River basin, China. Journal of Hydrology, 519, 387, 2014.

46. KONG D.X., MIAO C.Y., WU J.W., BORTHWICK A.G.L., DUAN Q.Y., ZHANG X.M. Environmental impact assessments of the Xiaolangdi Reservoir on the most hyperconcentrated laden river, Yellow River. Environ Sci Pollut Res, 24, 4337, 2017. 